\title{
A escritura anacrônica de Clarice Lispector: tarefa de traduzibilidade
}

\author{
The anachronistic writing of Clarice \\ Lispector: task of translatability
}

Davi Pessoa Carneiro Barbosa*

\section{RESUMO}

O artigo pretende confrontar o pensamento de Clarice Lispector acerca do "ser cronista", que, por sua vez, se relaciona com a questão do tempo em sua escritura. Tal questão, por outro lado, se desdobra numa percepção singular sobre tradução, bem como sobre outra noção temporal da escritura, a saber: o anacronismo. Há uma relação singular entre escritura e tradução, e é esta relação que nos interessa aqui discutir a partir de três pequenos textos publicados por Clarice no "Jornal do Brasil". O primeiro se chama "Quem escreveu isto?”. O segundo, “Tradução atrasada”, e o terceiro, um tanto misterioso, é a tradução do famoso texto "Borges y yo", de Jorge Luis Borges.

Palavras-chave: Clarice Lispector; traduzibilidade; anacronismo, crônica.

\section{ABSTRACT}

The present paper discusses some questions raised by Clarice Lispector about "being a chronicler," which, in turn, relates to the issue of time in her writing. This question, however, unfolds in a unique perception of translation, as well as another temporal notion of scripture, namely the anachronism. There is a unique relationship between writing and translation, and that is the relationship that interests us here, and we'll discuss it with three small texts published by Clarice in "Jornal do Brazil". The first is called "Quem escreveu isto?". The second, "Tradução atrasada", and the third, somewhat mysterious, is the translation of the famous text "Borges y yo" by Jorge Luis Borges.

Keywords: Clarice Lispector; translatability; anachronism; chronicle.

\footnotetext{
* Professor de Literatura Italiana da Universidade do Estado do Rio de Janeiro.
} 
O tempo se torna tempo humano em virtude da experiência que o homem faz dele. Mas o homem faz experiência do tempo transformando a experiência numa espécie de temporalidade. Há um círculo vicioso. O que é muito evidente caso pensemos que, de um lado, o homem faz experiência do tempo narrando o acontecido, isto é, dispondo os acontecimentos de acordo com a ordem de uma narração possivel, mas, por outro lado, os acontecimentos desde sempre são feitos de matéria narrativa, ou seja, eles em si mesmos já são narrações.

(GIVONE, 2005, p. 102) 
Barbosa,D.P.C.

A escritura anacrônica de

Clarice Lispector: tarefa de traduzibilidade
Revista Letras, Curitiba, UFPr, n. 95 109-122, jan./jun. 2017. ISSN 2236-0999 (versão eletrônica)
1 tarefa, aqui, é esboçar, brevemente, algumas linhas do pensamento de Clarice Lispector acerca do "ser cronista", que se relaciona com uma noção temporal distinta daquela cronológica. ${ }^{1}$ Tal operação se desdobra, também, numa percepção singular sobre tradução. Clarice traduziu alguns textos literários, principalmente durante o período entre os anos 1969-1979. Cito alguns: A rendeira (1975), de Pascal Lainé; Viagens de Guliver (1973), de Jonathan Swift; Testamento para el Greco (1975), de NikosKazantzakis; Chamado Selvagem (1970), de Jack London. Ela, ainda muito jovem, com 20 anos de idade, estudante da Faculdade Nacional de Direito, no Rio de Janeiro, começa a escrever para a revista $\mathrm{Pan}^{2}$, em 1940. Nela publica sua primeira ficção, a saber, a novela "Triunfo". Ainda em 1940, começa a trabalhar para a revista Vamos ler!; a edição de outubro do mesmo ano traz seu conto "Eu e Jimmy", cuja publicação vem acompanhada de ilustrações feitas por José Correia de Moura. Ainda na revista Vamos ler!, Clarice começa a viver suas primeiras experiências como

1 Este ensaio é uma versão reelaborada e ampliada da discussão iniciada em outro texto intitulado "Quem escreveu isto, a tradução em Clarice Lispector", publicado, em 2010, na revista "In-Traduções", n.3, vol. 2.

2 A revista Pan teve como diretor José Scortecci e teve circulação nacional entre os anos 1935 e 1940. Nela havia espaços para biografias, textos literários, pesquisas médicas e biológicas, viagens, além de matérias sobre a Segunda Guerra Mundial. 
entrevistadora ${ }^{3}$, e na edição de dezembro publica sua entrevista com o poeta Tasso da Silveira (1895-1968), intitulada "Uma hora com Tasso da Silveira", em que a escritora já demonstra certo interesse pela questão do tempo, como lemos na apresentação:

\begin{abstract}
Para mim, entrevistar Tasso da Silveira era continuar uma daquelas palestras tão profundas, nas quais eu assistia atenta o poeta revolver os grandes problemas do pensamento. Quando, na redação do "Pan", sua mesa não estava muito atulhada de papéis e seu cigarro não queimava rápido demais, eu puxava uma cadeira e, assim como quem nada quer, dizia uma palavra, uma simples palavrinha. E em breve discutíamos a gênese do mundo, a significação da arte, a explicação do tempo e da eternidade... Eram problemas para mim, certezas para ele.
\end{abstract}

(LISPECTOR, 2012, p. 39)

Seus textos ditos "jornalísticos", como sabemos, trazem uma série de questões acerca da escritura, da relação entre escritor e leitor, assim como discutem problemas relacionados aos ditos gêneros literários, além de tantos outros "problemas do pensamento".

Há, no entanto, uma indagação recorrente, ao longo de vários anos, nos textos publicados no "Caderno B" do Jornal do Brasil, entre 1967 e 1973, qual seja: ser ou não cronista? No artigo "Ser cronista”, publicado no Jornal do Brasil, 112 em 22 de junho de 1968, ou seja, quase três décadas depois do aparecimento de seu primeiro texto publicado na imprensa brasileira, a escritora ainda continuava a questionaro que seria uma "crônica":

Sei que não sou, mas tenho meditado ligeiramente no assunto. $\mathrm{Na}$ verdade eu deveria conversar a respeito com Rubem Braga, que foi o inventor da crônica. Mas quero ver se consigo tatear sozinha no assunto e ver se chego a entender. Crônica é um relato? É uma conversa? É o resumo de um estado de espírito? Não sei, pois antes de começar a escrever para o Jornal do Brasil, eu só tinha escrito romances e contos. Quando combinei com o jornal escrever aqui aos sábados, logo em seguida morri de medo.

(LISPECTOR, 1999, p. 112-113)

3 Na revista "Manchete", Clarice realizou entrevistas entre 1968 e 1969, sob a denominação de "Diálogos possíveis com Clarice Lispector". Entrevistou Nelson Rodrigues, Tom Jobim, Henrique Pongetti, José Carlos de Oliveira, Dona Sara, Tereza Souza Campos, Maísa. Na revista Fatos e Fotos/Gente, entrevistou Elke Maravilha, Mário Soares, Alzira Vargas do Amaral Peixoto, Darcy Ribeiro, Rubem Braga e Flora Morgan Snell. Algumas dessas entrevistas estão publicadas em: LISPECTOR, C. Clarice na cabeceira: jornalismo. Organização e apresentações de Aparecida Maria Nunes. Rio de Janeiro: Rocco, 2012.

4 LISPECTOR, C. "Uma hora com Tasso da Silveira", In: Clarice na cabeceira: jornalismo. Organização e apresentações de Aparecida Maria Nunes. Rio de Janeiro: Rocco, 2012, p. 39. 
Barbosa,D.P.C.

A escritura anacrônica de

Clarice Lispector: tarefa de traduzibilidade

As proposições de Clarice tencionam nossa compreensão sobre esse modo de escritura, tanto que nos cabe questionar: as "crônicas" publicadas em jornais narram apenas fatos cotidianos vividos pelas pessoas, cujo teor crítico (e também irônico) abole toda possibilidade da existência da ficção em detrimento de uma escrita dissertativa clara e objetiva? O termo "crônica", proveniente do latim "chronica", que por sua vez está relacionado ao termo grego "khrónos" (tempo), marca simplesmente uma narrativa em que acontecimentos estão ligados a um tempo determinado e linear? E sendo um texto voltado ao leitor do cotidiano, então ele precisa ter necessariamente seu caráter crítico de fácil acesso, com o intuito de divertir e informar o leitor? O texto "Ser cronista" ainda traz outra preocupação:

Outra coisa notei: basta eu saber que estou escrevendo para jornal, isto é, para algo aberto facilmente por todo o mundo, e não para um livro, que só é aberto por quem realmente o quer, para que, sem mesmo sentir, o modo de escrever se transforme. Não é que me desagrade mudar, pelo contrário. Mas queria que fossem mudanças mais profundas e interiores que então viessem a se refletir no escrever. Mas mudar só porque isto é uma coluna ou uma crônica? Ser mais leve só porque o leitor assim o quer? Divertir? Fazer passar uns minutos de leitura? E outra coisa: nos meus livros quero profundamente a comunicação profunda comigo e com o leitor. Aqui no jornal apenas falo com o leitor e agrada-me que ele fique agradado. Vou dizer a verdade: não estou contente. E acho mesmo que vou ter uma conversa com Rubem Braga porque sozinha não consegui entender.

(LISPECTOR, 1999, p. 113) $)^{5}$

Portanto, o título, embora não o traga explicitamente, parece indicar muito mais uma interrogação: "ser cronista?", pois a reflexão presente no relato é

Revista Letras, Curitiba, UFPR, n. 95 109-122, jan./jun. 2017. ISSN 2236-0999 (versão eletrônica)
5 Na revista Fatos e Fotos/Gente, Clarice entrevista Rubem Braga, em 1977, e na sua apresentação à entrevista, lemos: "Há mil 'rubens' dentro de Rubem Braga, é claro, assim como há mil 'clarices' em mim. E tanta coisa eu desconheço em Rubem, que era melhor entrevistá-lo de vez. Pelo menos tentarei atenuar o seu mistério (porque ele é um pouco misterioso)". Vale a pena transcrevermos, aqui, a segunda pergunta, que ela lhe faz, seguida de sua resposta: "- Você para mim é um poeta que teve pudor de escrever versos, e então inventou a crônica (pois foi você quem inventou esse gênero de literatura), crônica que é poesia em prosa, em você. É ou não é?". "- Não é bem isso. Há um fato importante em minha carreira: eu sempre escrevi para jornal. A partir do Correio do Sul, de Cachoeiro de Itapemirim, que era de meu irmão Armando e chegou a sair três vezes por semana. Lá publiquei alguns versos mas escrevia principalmente artigos terrivelmente sérios sobre política, lavoura, economia etc., e uma ou outra crônica ligeira. Em suma: eu escrevia o que me dava na telha e, na verdade, nunca tive pudor de fazer versos. É que fazer bons poemas (em versos) exige um tipo de habilidade e de economia, síntese e ao mesmo tempo, desculpem a palavra, inspiração. É muito mais fácil ir na cadência da prosa, e quando acontece ela dizer alguma coisa poética, tanto melhor”. In: LISPECTOR, Clarice na cabeceira, Op. cit., p. 229-230. 
a do não entendimento, ou, poderíamos dizer através do pensamento de Georges Bataille, do "não-saber", que não é o apagamento do saber, senão o saber levado ao seu excesso. E esta compreensão de dispêndio se encontra justamente em um texto que traz uma experiência limite: "O grito": "Sei que o que escrevo aqui não se pode chamar de crônica nem de coluna nem de artigo. Mas sei que hoje é um grito. Um grito!”. (LISPECTOR, 1999, p. 81) Nesse sentido, o confronto com o não entendimento (ou com o entendimento levado ao limite) desarticula certas estruturas rígidas e intocáveis. Não por acaso, um dos textos publicados no Jornal do Brasil se chama "Não entender”. E se o objetivo não é apreender algo, fixando-o em categorias fechadas, mas muito mais tocar algo como gesto de liberdade, como gesto de traduzibilidade; então, torna-se simplista e categórico afirmar que os textos publicados por Clarice Lispector, no Jornal do Brasil, são crônicas. Em a "Máquina escrevendo", lemos: "Vamos falar a verdade: isto aqui não é crônica coisa nenhuma. Isto é apenas. Não entra em gênero. Gêneros não me interessam mais. Interessa-me o mistério. Preciso ter um ritual para o mistério? Acho que sim". (LISPECTOR, 1999, p. 347) No texto "Ficção ou não", também lemos uma reflexão sobre gêneros:

Mas é que me surpreende um pouco a discussão sobre se um romance é ou não romance. No entanto as mesmas pessoas que não o classificam de romance falam de seus personagens, discutem seus motivos, analisam suas soluções como possíveis ou não, aderem ou não aos sentimentos e pensamentos dos personagens. O que é ficção? [...] Mas exatamente o que não quero é a moldura. [...] Mas para escrever quero prescindir de tudo o que eu puder prescindir: para quem escreve, essa experiência vale a pena.

(LISPECTOR, 1999, p. 270-271)

Michel Foucault, em 1963 (ou seja, durante o mesmo período em que Clarice estava escrevendo para jornais e revistas), escreve para a revista Critique (n ${ }^{\circ}$ 198) o ensaio "Distância, aspecto, origem". Foucault nos chama a atenção de que "não há ficção porque a linguagem está distante das coisas; mas a linguagem é sua distância” (FOUCAULT, 2006, p. 69), ou seja, a linguagem é essa distância, esse vazio, essa translação que monta uma temporalidade não linear, ou melhor, poderíamos dizer, monta uma série anacrônica. A linguagem da ficção é, portanto, uma espécie de simulacro, e "qualquer linguagem que, em vez de esquecer essa distância, se mantém nela e a mantém nela, qualquer linguagem que fale dessa distância avançando nela é uma linguagem de ficção". (FOUCAULT, 2006, p. 69) E tal linguagem, tão presente quanto ausente, nos diz Foucault - e de modo muito similar ao pensamento de Clarice Lispector: "é possível então atravessar qualquer prosa e qualquer poesia, qualquer romance e qualquer reflexão, indiferentemente”. (FOUCAULT, 2006, p. 69) 
Barbosa,D.P.C.

A escritura anacrônica de

Clarice Lispector: tarefa de traduzibilidade

Clarice Lispector, em 1967 - primeiro ano como colaboradora do Jornal do Brasil - já demonstrava certo incômodo acerca de sua nova função na imprensa brasileira, assim como não se sentia bem de ter que escrever para "ganhar dinheiro": "Ainda continuo um pouco sem jeito na minha nova função daquilo que não se pode chamar propriamente de crônica. E, além de ser neófita no assunto, também o sou em matéria de escrever para ganhar dinheiro". (LISPECTOR, 1999, p. 29) Ela também se sentia muito incomodada pelo fato de assinar seus textos, pois, segundo ela: "assinando fico automaticamente mais pessoal”. (LISPECTOR, 1999, p. 29)

Eis o ponto: assinando fico automaticamente mais pessoal. Há três textos publicados, igualmente, no Jornal do Brasil, que chamam a nossa atenção pelo fato de que a tradução se torna precisamente uma estratégia de reflexão sobre a diluição da assinatura de uma escritura. O primeiro deles se chama "Quem escreveu isto?", publicado no dia primeiro de março de 1969. O segundo, "Tradução atrasada", publicado em 25 de abril de 1970. O terceiro fragmento, um tanto misterioso, é a tradução do famoso texto "Borges y yo", de Jorge Luis Borges, que foi publicado no dia 22 de março de 1969, o qual não foi incluído na edição de $A$ descoberta do mundo e ao qual só tive acesso alguns anos atrás, em Florianópolis, quando li a dissertação de mestrado de Célia Regina Ranzolín, intitulada "Clarice Lispector cronista no Jornal do Brasil (1967-1973)", defendida em 1985, no curso de Letras, da Universidade Federal de Santa Catarina.

Destacando mais uma vez as proposições "Ser cronista" e "assinando fico automaticamente mais pessoal”, começarei por um texto emblemático já em seu título, pois parece marcar essa zona indiscernível, na qual se encontra uma sorte de "terceira pessoa". Cito-o na íntegra:

\section{QUEM ESCREVEU ISTO?}

Andei mexendo em papéis antigos e encontrei uma folha onde estavam escritas, entre aspas, algumas linhas em inglês. O que significa que eu copiei as linhas de tão belas que as achei. No entanto não estava anotado o nome do escritor, o que é imperdoável. Vou tentar traduzir e não sei se a tradução conservará esse algo que me tocou tanto: "Então por um momento os dois se apagaram na doce escuridão tão profunda que eles eram mais escuros que a escuridão, por uns instantes ambos eram mais escuros que as negras árvores, e depois tão escuro que, quando ela tentou erguer os olhos até ele, só pôde ver as ondas selvagens do universo acima dos ombros dele, e então ela disse: 'Sim, acho que eu também te amo'".

(LISPECTOR, 1999, p. 180)

Revista Letras, Curitiba, UFPR, n. 95 109-122, jan./jun. 2017. ISSN 2236-0999 (versão eletrônica) 
O título do artigo também marca, como se pode observar, uma ambivalência: "quem escreveu isto?" pode significar a ausência do escritor, que Clarice não recorda mais ("o que é imperdoável”) e pode significar, ao mesmo tempo, a presença da indecidibilidade na própria escritura. Tal escritura seria, assim, uma espécie de semblante? Alain Badiou (2007), na conferência "Paixão pelo real e montagem do semblante", destaca a importância de se pensar a função do semblante como paixão pelo real no século XX. Há uma passagem em $A$ paixão segundo G. H. em que ouvimos a impessoalidade presente no semblante da escritura: "O que os outros recebem de mim reflete-se então de volta para mim, e forma a atmosfera do que se chama: eu” (LISPECTOR, 2009, p. 27).

Cito, agora, o segundo fragmento escrito por Clarice, pois a partir dele podemos pensar o devir da (re)-escritura, tal como pensava Walter Benjamin:

\section{TRADUÇÃO ATRASADA}

Como epígrafe de meu romance, A paixão segundo G.H., escolhi, ou melhor, caiu-me por milagre nas mãos, depois do livro escrito, uma frase de Bernard Berenson, o crítico de arte. Usei-a como epígrafe, talvez sem mesmo que tivesse muito a ver com o livro, mas não resisti à tentação de copiá-la. Só que cometi um erro: Não a traduzi, deixei em inglês mesmo, esquecendo de que o leitor brasileiro não é obrigado a entender outra língua. A frase em português é: "uma vida completa talvez seja a que termine em tal plena identificação com o não-eu, que não resta nenhum eu para morrer”. Em inglês fica mais íntegra a frase, além de mais bonita.

(LISPECTOR, 1999, p. 283)

Nesse caso, a tradução da epígrafe não realizada por Clarice Lispector, no momento em que o livro foi publicado, indica o porvir da própria tradução, ou em outras palavras: trata-se de traduzibilidade. Como sabemos, para Benjamin:

A tradução é uma forma. Para compreendê-la como tal, é preciso retornar ao original. Pois nele reside a lei dessa forma, enquanto encerrada em sua traduzibilidade. A questão da traduzibilidade de uma obra possui um duplo sentido. Ela pode significar: encontrará a obra jamais, dentre a totalidade de seus leitores, seu tradutor adequado? Ou então, mas propriamente: admitirá ela, em conformidade com sua essência, tradução e, consequentemente (em consonância com o significado dessa forma), a exigirá também?

(BENJAMIN, 2001, p. 191) 
Barbosa,D.P.C.

$A$ escritura anacrônica de

Clarice Lispector: tarefa de traduzibilidade

Benjamin parece postular que a origem é sempre póstuma e postiça, já que a tarefa do tradutor é a traduzibilidade e não exclusivamente a tradução. Ainda segundo Benjamin: "A traduzibilidade é, em essência, inerente a certas obras; isso não quer dizer que sua tradução seja essencial para elas, mas que um determinado significado inerente aos originais se exprime na sua traduzibilidade" (BENJAMIN, 2001, p. 193). Assim, a origem e, portanto, o original, é a passagem da forma ao informe, é uma metamorfose. Ainda: se a tradução é uma forma, a traduzibilidade é uma força, tal como aquela das placas tectônicas que provocou o famoso terremoto de Lisboa.

O título dado por Clarice ao artigo, "tradução atrasada", é emblemático. E embora a escritora ache mais bonita e íntegra a frase em inglês, ela não hesitou publicá-la, em 1964, em A paixão segundo G.H., e traduzi-la, seis anos após a publicação de seu romance. $\mathrm{O}$ enunciado em inglês (" $A$ complete lifemay be oneending in sofullidentificationwiththenonself thatthereis no self to die", de Bernard Berenson) para Clarice já era outro: traduzir significava estabelecer a relação ser-com, isto é, ser com o diferente. E este parece ser o gesto mais potente da tradução. Importante ressaltar a questão da origem não como gênese, pois o conceito de origem, para Walter Benjamin, não aponta uma identidade, mas, ao contrário, assinala um movimento, uma alteridade. Poderíamos dizer: há algo que não cessa de passar e de desaparecer, dessa maneira o conceito de origem surge do processo de "vir-a-ser", e quando algo advém logo desaparece.

O terceiro texto, a tradução de Clarice do texto "Borges y yo", de Jorge Luis Borges, como indiquei anteriormente, é um caso mais misterioso - e o mesmo não foi incluído na seleção de $A$ descoberta do mundo. Célia Regina Ranzolin, em sua dissertação "Clarice Lispector Cronista: no Jornal do Brasil (1967-1973)”, organiza toda a produção de crônicas que Clarice escreveu para o JB, no período que vai de agosto de 1967 até dezembro de 1973. Segundo suas pesquisas, em 22 de março de 1969, Clarice publica "uma 'prosa' de Jorge Luis Borges - Borges e eu”, ou seja, a priori, a tradução do famoso texto de Borges:

Ao outro, ao Borges, é a quem ocorrem as coisas. Eu caminho por Buenos Aires e me demoro, talvez já mecanicamente, a olhar o arco de um saguão ou um portão de ferro: de Borges tenho notícias pelo Correio e vejo meu nome escrito em uma comissão de professores ou num dicionário biográfico. Agradam-se os relógios das praças, os mapas, a tipografia do século XVIII, o sabor de café e a prosa de Stevenson: o outro compartilha dessas preferências, mas de um modo vaidoso que as converte em atributos de ator. Seria exagerado afirmar que nossa relação é hostil: eu, vivo, eu me deixo viver para que Borges possa tramar sua literatura e essa literatura me justifica. Nada me custa confessar que tem conseguido páginas válidas, mas essas páginas não podem me salvar talvez porque o bom

Revista Letras, Curitiba, UFPR, n. 95 109-122, jan./jun. 2017. ISSN 2236-0999 (versão eletrônica) 
já não é de ninguém nem sequer do outro, se não da literatura ou da tradição. Por outro lado, já estou destinado a perder-me, definitivamente, e só algum instante de mim poderá sobreviver ao outro. Pouco a pouco vou cedendo-lhe tudo, ainda que conheça seu perverso costume de falsear e engrandecer. Spinosa entendeu que todas as coisas querem perseverar em seu ser: a pedra eternamente pedra quer ser pedra e o tigre um tigre. Eu hei de permanecer em Borges, não em mim (se é que sou alguém), mas menos em seus livros que em muitos outros momentos ou do que no ponteio de uma guitarra.

Há muitos anos eu tratei de livrar-me dele e passei das mitologias do bairro aos jogos com o tempo e números, e com o infinito, mas esses jogos são de Borges agora e terei de imaginar outras coisas. Assim minha vida é uma fuga e tudo tenho perdido e tudo é do esquecimento ou do outro.

Não sei qual dos dois escreve esta página (LISPECTOR, 1969, Jornal do Brasil, do livro El Hacedor, de JLB).

O que há de mais interessante no jogo realizado por Clariceé o que vem logo após, o a posteriori, que, aliás, parece ser a continuação da tradução, tomada pelo enunciado que finaliza "Borges y yo": "Não sei qual dos dois escreve esta página". Segundo o crítico Raúl Antelo, que também irá investigar a aparição desse texto no JB, tal estratégia não é muito diferente daquela realizada por Clarice em $A$ Paixão segundo G.H., na qual lemos o último enunciado de cada "capítulo" sendo retomado no início do capítulo posterior.Antelo, no ensaio "La traducción infinita”, coloca em evidência a estratégia de Clarice Lispector, ao incluir um texto-suplemento que não é de Borges e que, ao mesmo tempo, não passa de uma premissa muito ao modo de Borges: a atribuição errônea. Segundo Antelo:

Repárese, sin embargo, que asumiendo, como em $A$ Paixão segundo G.H., el final del antecedente, "não sei qual dos dois escreve esta página”, como inicio del fragmento consecuente, podríamos pensar que Clarice agrega un suplemento a esa "traducción", obedeciendo también a la premisa de la atribución errónea, una regla central de la poética de Borges”.

(ANTELO, 2008, p. 139)

Cito agora o suplemento escrito por Clarice:

E agora vamos ao que há de mais velho e permanente e teimoso do mundo: Números - disse teimoso porque nada consegue modificá-los. Não há nada para atrapalhar-lhes a carreira, através dos tempos, numa semântica. O número é 
Barbosa,D.P.C.

A escritura anacrônica de

Clarice Lispector: tarefa de traduzibilidade como o destino, sim, um desafio a tudo. Ele simplesmente é. Não há nascimento, nem vida, nem morte do número. É uma norma, uma lei, um ritmo.

Para Pitágoras o número é esta ordem, esta coerência que transmite a idéia de uma tensão de um todo, o kosmos oposto ao kaos, embora este termo não deva ser entendido no seu sentido vulgar, mas no do que ele é um pré-kosmos, onde estão contidas todas as possibilidades do vir-a-ser-kosmos. Todas as coisas, pelo menos as que são conhecidas, tem número, pois não é possível que uma coisa qualquer seja pensada ou conhecida sem número.

Já lhe disse hoje que o número possui duas formas próprias: o ímpar e o par. A combinação dessas duas formará uma terceira: o par-ímpar. A paridade é infinita à nossa volta e através dela podemos com-parar. Ao passo que as coisas ímpares são menos incom-paráveis. Aqui estamos em pleno caminho para descobertas maravilhosas. A unidade suprema - o um, que não é número, pois nele não há participação... (LISPECTOR, 1969, Jornal do Brasil, El Hacedor, de JLB).

Raúl Antelo, assim, observa e traz à tona o disfarce ou a presença do terceiro elemento nesse processo, pois não é mais a figura do escritor (Borges) e da tradutora (Clarice) que está em questão, mas a indecidibilidade, pois quem é quem nesse jogo? Segundo Antelo: "Obviamente, el texto no es de Borges, ni siquiera de JLB, personaje emparentado, por su laconismo, con G.H." (ANTELO, 2008, p. 140) E o processo que se experimenta através dessa reflexão se dá no hiato entre cada um desses polos. A tradução, assim sendo, seria o palimpsesto que não para de aparecer e que possibilita sempre a aparição do texto por vir. Além do mais, importante destacar, no suplemento de Clarice Lispector, uma outra característica muito presente na ficção de Jorge Luis Borges: a questão dos números. Lembro do pequeno texto, em El Hacedor, "argumentum ornithologicum”, em que aparece a problemática do número relacionado a Deus: "Se Deus existe, o número é definido, porque Deus sabe quantos pássaros vi. Se Deus não existe, o número é indefinido, porque ninguém conseguiu fazer a conta” (BORGES, 2008, p. 19).

Clarice, portanto, se insere no processo de escritura-tradução movida por um desejo que é singular e radical: o da impessoalidade. A tradução também não marcaria esse devir, visto que o tradutor se insere no processo movido pelo desejo de re-escrever um determinado texto consciente do caráter provisório da própria tradução, e muito mais, consciente que se faz necessária uma espécie de abandono da hegemonia do "eu"? Assim, o palimpsesto de Borges e de Clarice
Revista Letras, Curitiba, UFPr, n. 95 109-122, jan./jun. 2017. ISSN 2236-0999 (versão eletrônica) 
busca a potencialidade e a heterogênese dos textos, tal como pensava Walter Benjamin. Clarice, nos textos publicados no JB, aqui discutidos, parece indicar essa metamorfose. O primeiro, "Quem escreveu isto?", marca uma indecidibilidade, do mesmo modo como Borges finaliza seu texto: "Não sei qual dos dois escreve esta página”. O segundo, "tradução atrasada”, marca um por vir, algo que não para de se repetir, no entanto, ao se repetir não traz o mesmo novamente, mas uma diferença. E o terceiro é um jogo, ou um "brincar de pensar”, pois:

Entregar-se a pensar é uma grande emoção, e só se tem coragem de pensar na frente de outrem quando a confiança é grande a ponto de não haver constrangimento em usar, se necessário, a palavra outrem. Além do mais exige-se muito de quem nos assiste pensar: que tenha um coração grande, amor, carinho, e a experiência de também se ter dado ao pensar.

(LISPECTOR, 1999, p. 23)

Porém, toda brincadeira possibilita correr riscos: "Às vezes começa-se a brincar de pensar, e eis que inesperadamente o brinquedo é que começa a brincar conosco. Não é bom. É apenas frutífero". (LISPECTOR, 1999, p. 23) A tarefa da traduzibilidade é também uma questão de método, e colocar esse método em ação é uma questão de fazer conviver, mesmo que em estado de luta, tempos mais disparatados possíveis, rompendo com uma concepção cronológica de tempo. A meu ver, esse é um ponto fundamental para se pensar a escritura 120 de Clarice Lispector, cujos desdobramentos se potencializaram os "problemas de pensamento" acerca daquilo que se compreende como "crônica" e "tradução", visto que ambas mais que um fim sem meios são, por outro lado, meios sem fim, ou ainda, são questões de traduzibilidade, de processo, no qual outra compreensão temporal ganha importância nessa experiência. Do mesmo modo, a tarefa de traduzibilidade é um jogo, e pode levar o jogador à loucura. Maurice Blanchot nos relata o caso clínico de Hölderlin:

O exemplo de Hölderlin mostra, concluindo, o risco que corre o homem fascinado pela potência da tradução: as traduções de Antigona e de Édipo foram, mais ou menos, as suas últimas obras, na soleira da loucura, obras extremamente meditadas, controladas, escolhidas e conduzidas com inflexível firmeza. Seu objetivo não era levar o texto grego à língua alemã, nem levar a língua alemã às fontes gregas, mas queria, por outro lado, unificar as duas forças que trazem em si: uma com as vicissitudes do Ocidente, a outra com as do Oriente, na simplicidade de uma língua total e pura. $\mathrm{O}$ resultado é quase terrível. Ele acredita ter descoberto nas duas línguas um pacto tão profundo, uma harmonia tão fundamental, capaz 
Barbosa,D.P.C.

A escritura anacrônica de

Clarice Lispector: tarefa de traduzibilidade de substituir o seu sentido ou capaz de fazer do hiato que se abre entre elas a origem de um novo sentido. $\mathrm{O}$ efeito é tão poderoso que se compreende a risada fria de Goethe. Do que ria Goethe? De um homem que não era mais nem poeta, nem tradutor, mas que se encaminhava arrojadamente em direção ao centro em que acreditava encontrar reunido o puro poder de unificação, tanto que poderia dar um sentido para além de todo sentido determinado e limitado. Podemos entender que essa tentação tenha sido provocada em Hölderlin pela tradução; porque o homem pronto a traduzir está numa intimidade constante, perigosa, exemplar, com o poder unificador da obra em toda relação prática, igualmente como em toda linguagem, colocando-o, ao mesmo tempo, na pura cisão inicial. É dessa familiaridade que ele traz o direito de ser, entre os escritores, o mais orgulhoso ou o mais secreto - com a convicção de que traduzir, no final das contas, é loucura.

(BLANCHOT, 1971, p. 72-73, tradução nossa)

$\mathrm{Ou}$, ainda, é um jogo anotado em um caderno de notas: "Todos aqueles que fizeram grandes coisas fizeram-nas para sair de uma dificuldade, de um beco sem saída". Traduzo isso do francês, frase encontrada num caderno de notas antigo. Mas, quem escreveu isso? Quando? Não importa, é uma verdade de vida, e muitos poderiam tê-la escrito." (LISPECTOR, 1999, p. 399) Em última análise, a escritura de Clarice é uma tarefa de traduzibilidade. 


\section{Referências}

ANTELO, R. Crítica acéfala. Buenos Aires: Editorial Grumo, 2008.

BADIOU, A. O século. Trad. Carlos Felício da Silveira. São Paulo: Idéias\& Letras, 2007.

BENJAMIN, W. A tarefa-renúncia do tradutor. In: HEIDERMANN, Werner (org.). Clássicos da teoria da tradução. Trad. Susana Kampff Lages. Florianópolis: UFSC, 2001, p. 189-214.

BLANCHOT, M. "A solidão essencial”. In: O espaço literário. Trad. Álvaro Cabral. Rio de Janeiro: Rocco, 2011, p. 9-26.

$62-73$. “Traduire”.In: L’amitié. Paris: Editions Gallimard, 1971, p.

BORGES, J. L. O Fazedor. Trad. Josely Vianna Baptista. São Paulo: Companhia das Letras, 2008.

FOUCAULT, M. "Distância, aspecto, origem". In: Estética: Literatura e Pintura, Música e Cinema. Trad. Inês Autran Dourado Barbosa. 2 ed. Rio de Janeiro: Forense Universitária, 2006, p. 60-74.

GIVONE, S. Il bibliotecario di Leibniz: filosofia e romanzo. Torino: Einaudi, 2005.

122 LISPECTOR, C. Clarice na cabeceira: jornalismo. Organização e apresentações de Aparecida Maria Nunes. Rio de Janeiro: Rocco, 2012.

A descoberta do mundo. Rio de Janeiro: Rocco, 1999.

"Borges e eu”, in: Jornal do Brasil, 1969.

RANZOLIN, C. R. Clarice Lispector Cronista: no Jornal do Brasil (1967-1973).426 f. Dissertação (Pós-Graduação em Literatura Brasileira) Departamento de Língua e Literatura Vernáculas, UFSC, Florianópolis, 1985.

Submetido em: 19/10/2016

Aceito em: 22/12/2016 